\title{
Correction to: Qualitative Attribution, Phenomenal Experience and Being
}

\section{Mark Pharoah ${ }^{1}$}

Published online: 11 April 2019

(C) Springer Nature B.V. 2019

\section{Correction to: Biosemiotics}

\section{https://doi.org/10.1007/s12304-018-9344-9}

In the article Qualitative Attribution, Phenomenal Experience and Being, by Mark Pharoah, the following corrections have been made.

\section{Correction 1 .}

-Page 5 currently reads,

$>$ This point highlights a bifold distinction which Merleau-Ponty (1963) explores indepth. A mechanical action, whether the word is taken in a restricted or looser sense, is one in which the cause and the effect are decomposable into real elements which have a one-to-one correspondence (p. 160).

The correct text should be:

$>$ This point highlights a bifold distinction which Merleau-Ponty (1963) explores indepth. "A mechanical action, whether the word is taken in a restricted or looser sense, is one in which the cause and the effect are decomposable into real elements which have a

The online version of the original article can be found at https://doi.org/10.1007/s12304-018-9344-9

Mark Pharoah

markpharoah1@gmail.com

13 Avondale Road, London SE9 4SN, UK 
one-to-one correspondence" (p. 160).

\section{Correction 2.}

Page 8 currently reads,

$>$ My suggestion is that this inquiry can be explored through the notion of qualitative relevance. The Oxford English Dictionary defines "qualitative" as "pertaining to or concerned with quality, where quality relates to merit or value". The idea is that biochemical assimilation must assign not a direct or static attribution of merit to environmental particulars, but rather a qualitative attribution whose merit can subsequently be qualified by the relevance that those attributions might (or might not) have on an individual's changing needs and survival demands.<.

This should be:

$>$ My suggestion is that this inquiry can be explored through the notion of qualitative relevance ${ }^{1}$. The idea is that biochemical assimilation must assign not a direct or static attribution of merit to environmental particulars, but rather a qualitative attribution whose merit can subse- quently be qualified by the relevance that those attributions might (or might not) have on an individual's changing needs and survival demands. $<$.

Springer wishes to apologize for any inconvenience caused.

Publisher's Note Springer Nature remains neutral with regard to jurisdictional claims in published maps and institutional affiliations.

\footnotetext{
${ }^{1}$ The Oxford English Dictionary defines "qualitative" as "pertaining to or concerned with quality, where quality relates to merit or value" 